\title{
Effectiveness of Train the Trainers Program in Improvement of Oral Health of Children in Tamilnadu - A Randomized Trial
}

\author{
Lalitha Rani Chellappa', S.S Raj'2, Meignana Arumugham Indiran³ and Pradeep kumar \\ Rathinavelu ${ }^{4}$ \\ ${ }^{1}$ Post Graduate, Department of Public Health Dentistry Saveetha Dental College Saveetha \\ Institute of Medical and Technical Sciences Saveetha University Chennai, India \\ ${ }^{2}$ Associate Professor, Department of Public Health Dentistry Saveetha Dental College \\ Saveetha Institute of Medical and Technical Sciences Saveetha University Chennai, India \\ ${ }^{3}$ Professor and Head, Department of Public Health Dentistry Saveetha Dental College \\ Saveetha Institute of Medical and Technical Sciences Saveetha University Chennai, India \\ ${ }^{4}$ Professor and Head, Department of Public Health Dentistry Saveetha Dental College \\ Saveetha Institute of Medical and Technical Sciences Saveetha University Chennai, India
}

\section{ABSTRACT}

School years are influential stages in people's lives where lifelong substantial oral health-related behaviours, as well as beliefs and attitudes, are being developed. Children are particularly receptive during this period, and the earlier habits are established, the long-lasting, and the impact. The aim of the study is to assess the Effectiveness of Train the trainers program in improvement of oral health of children in rural Tamilnadu. In this double blinded trial, 100 schools were selected from each Tiruvallur and Kanchipuram districts by computer generated randomized sequence (CGRS). 50 schools in each district were chosen as control and the other 50 in the test group.The oral hygiene of the children was assessed with DMFT and QH plaque index (with dissolved disclosing solution) and fracture of teeth was assessed with Elli's Classification. The children were enquired regarding their diet sugar intake frequency, brushing frequency, fluoride toothpaste etc. Oral health education , brushing techniques and oral hygiene instruction were taught to Block Resource Teacher Educators (BRTE) and trainers in the test group schools alone. After that a follow up has been done after 6 months for the final data. The data was entered in Google forms and analysed in IBM SPSS software version 20.0.Student $\mathrm{T}$ test was used to compare the baseline data and 6 month follow up data between the 2 groups and $\mathrm{p}$ value was kept at $<0.05$ for significance. Results showed that in baseline DMF components were $1.47 \pm 0.95,0.12 \pm 0.08$ and $0.1 \pm 0.04$ respectively and after the follow up, it was $1.26 \pm 0.71,0.09 \pm 0.05$ and $0.1 \pm 0.07$ respectively. Likewise in primary dentition, $\mathrm{dmf}$ components were $1.71 \pm 0.92,0.14 \pm 0.09$ and $0.019 \pm 0.02$ in the baseline data and $1.2 \pm 0.8 ; 0.11 \pm 0.06$ and $0.15 \pm 0.082$ final data respectively. Before intervention,only 30.9\% were brushing twice daily but after the intervention, $69.5 \%$ were brushing twice. Similarly $11.5 \%$ were using the proper brushing technique before the intervention but it increased to $81.2 \%$ after the intervention. The present study shows significant difference in brushing frequencies, oral hygiene status which shows the train the trainees program was successful even with limitations.

KEY WORDS: PLAQUE, ORAL HEALTH, CHILDREN, BRUSHING FREQUENCY,HEALTH EDUCATION.

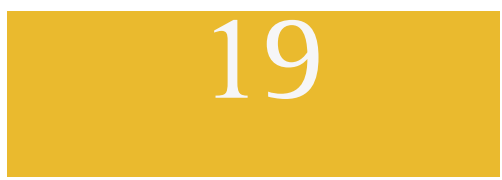




\section{ARTICLE INFORMATION}

*Corresponding Author: samuelrajs.sdc@saveetha.com Received 10th July 2020 Accepted after revision 24th Sep 2020 Print ISSN: 0974-6455 Online ISSN: 2321-4007 CODEN: BBRCBA

Thomson Reuters ISI Web of Science Clarivate Analytics USA and Crossref Indexed Journal

\section{Clarivate
Analytics}

NAAS Journal Score 2020 (4.31) SJIF: 2020 (7.728)

A Society of Science and Nature Publication,

Bhopal India 2020. All rights reserved.

Online Contents Available at: http//www.bbrc.in/

Doi: http://dx.doi.org/10.21786/bbrc/13.8/4

\section{INTRODUCTION}

Health is a basic human right and oral health is a significant component of general health. Although oral diseases are mostly not life - threatening, they are important public health problems. The reasons for their importance are their high prevalence, public demand, and their impact on individuals and society in terms of pain and discomfort and effect on the quality of life(Al-Haddad et al., 2013) Oral health is a prime aspect of the overall health status of an individual. Teeth and their supporting (periodontal) structures are of main importance to oral health.(Last and Wallace, 1992; Gopalakrishnan et al., 2012) Oral health care in rural areas is limited due to shortage of dental manpower, financial constraints and the lack of perceived need for dental care among rural masses. One of the most important factors to be considered when planning for the improvement in dental care facilities in rural India is the baseline data for dental diseases and the treatment needs of the population(Saravanan et al., 2008)

School years wraps a period that runs from childhood to adolescence. These are influential stages in people's lives where lifelong substantial oral health-related behaviours, as well as beliefs and attitudes, are being developed. Children are particularly receptive during this period, and the earlier habits are established, the long-lasting, and the impact.(Goel et al., 2014).Children who suffer from poor oral health are 12 times more likely to have more restricted activity days including missing schools than those who do not(Organization and Others, no date). Dental caries are a multifactorial disease and are the outcome of a multiple complex process involving factors such as diet, microorganisms, trace elements, saliva, genetic predisposition, and tooth morphology. Apart from these, many related factors such as individual, social, environmental, and cultural factors are also responsible(Doifode, Ambadekar and Lanewar, 2000; Lukacs and Largaespada, 2006; Saxena and Shashikiran, 2010; Naziya et al., 2017).

The oral health of primary school children is poor and there is a dire need to improve the oral health behavior of less privileged children from rural areas in Tamilnadu. These children may come from a background in which the parents won't be much aware of their oral health. Therefore it is ideal to teach them health education through the teachers in their school. Also the knowledge , attitude of parents and children towards oral health is much important to improve the oral health of the children and behaviour change is essential (Priya et al., 2013, 2019; Gurunathan, Moses and Arunachalam, 2018; Mk and Umadevi, 2020) It is suggested that a holistic approach to development of healthy lifestyles and creation of healthy environments is needed in schools and families to promote oral health of schoolchildren and it is proven that involving the teachers in oral health promotion has proven effective (Jürgensen, Petersen and Others, 2013; Petersen et al., 2015)

We have successfully completed numerous epidemiological studies for the betterment of our community. (Prabakar, John and Srisakthi, 2016; Kannan et al., 2017; Kumar and Preethi, 2017; Kumar, Pradeep Kumar and Vijayalakshmi, 2017; Prabakar, John, I. Arumugham, et al., 2018; Prabakar, John, I. M. Arumugham, Kumar and Sakthi, 2018; Prabakar, John, I. M. Arumugham, Kumar and Srisakthi, 2018; Vishnu Prasad et al., 2018; Harini and Leelavathi, 2019; Khatri et al., 2019; Manchery et al., 2019; Mohapatra et al., 2019; Neralla et al., 2019; Pavithra, Preethi Pavithra and Jayashri, 2019; Pratha and Prabakar, 2019; Shenoy, Salam and Varghese, 2019; Mathew et al., 2020; Samuel, Acharya and Rao, 2020). In this research we are analyzing the Effectiveness of train the trainers program in improvement of oral health of children in rural Tamilnadu.

\section{MATERIAL AND METHODS}

The study was a randomized trial conducted in the Tiruvallur and Kanchipuram districts of Tamil Nadu, South India. The study period was from August 2019 to March 2020. Ethical approval was obtained from the Institutional ethical board. 100 schools were selected from each Tiruvallur and Kanchipuram districts by computer generated randomized sequence (CGRS). 50 schools in each district were taken as control group (A) and the other 50 in the test group(B). The study was a double blinded trial. Oral screening was done and a set of questions were asked to 4 random students from class 3,4 ,and 5 each. The demographic details, like the name and age was obtained from school records. Questions about brushing frequency, brushing technique, use of fluoridated toothpaste, frequency of parents brushing per day and number of sugared snacks they consume per day has been asked and recorded. The questions were asked in a friendly, comprehensive and in local language to the children. The oral hygiene of the children was assessed with DMFT index (1938), QH plaque index and fracture of teeth was assessed with Elli's Classification.

The set of questions asked were frequency of brushing, use of fluoridated toothpaste, the frequency and quantity of sugared snacks consumed in a day and whether they have had any previous lessons of health education. The DMFT was used to measure the number of caries, missing and filled teeth(Klein, Palmer and Knutson, 1938) . QH 
plaque index was used to measure the plaque score. (Turesky, Gilmore and Glickman, 1970) The fractured teeth were recorded according to Ellis classification of fracture. After the baseline data has been recorded, oral health education, brushing techniques and oral hygiene instruction were taught to Block Resource Teacher Educators (BRTE) and trainers in the test group schools alone. This program was conducted for 3 days and one teacher from each test group school participated. Tooth brushes, toothpastes and mouthwashes were provided in the program. After that a follow up has been done after 6 months for the final data. The data was entered in Google forms and analysed in IBM SPSS software version 20.0. Descriptive statistics was done to assess the distribution of the variables. Student T test was used to compare the variables between the groups and Paired $\mathrm{T}$ test used to compare the variables within the group at baseline and follow up data and p value was kept at $<0.05$ for significance

Table 1. Comparative distribution of parameters among both groups at baseline and follow up using paired $\mathrm{T}$ test

\begin{tabular}{|c|c|c|c|c|c|c|}
\hline \multirow[b]{2}{*}{ Parameters } & \multicolumn{2}{|c|}{ Study group } & \multicolumn{4}{|c|}{ Control group } \\
\hline & $\begin{array}{l}\text { Baseline } \\
\text { (mean) }\end{array}$ & $\begin{array}{c}\text { Follow } \\
\text { up (mean) }\end{array}$ & $P$ value & Baseline & Follow up & $\mathrm{P}$ value \\
\hline $\mathrm{D}$ & $1.47 \pm 0.95$ & $1.26 \pm 0.71$ & $0.001^{*}$ & $1.37 \pm 0.34$ & $1.31 \pm 0.76$ & 0.06 \\
\hline M & $0.12 \pm 0.08$ & $0.09 \pm 0.05$ & 0.09 & $0.83 \pm 0.05$ & $0.71 \pm 0.04$ & 0.08 \\
\hline $\mathrm{F}$ & $0.1 \pm 0.04$ & $0.1 \pm 0.07$ & 0.12 & $0.09 \pm 0.03$ & $0.1 \pm 0.04$ & 0.14 \\
\hline $\mathrm{d}$ & $1.71 \pm 0.92$ & $1.2 \pm 0.8$ & 0.04 & $1.51 \pm 0.63$ & $1.34 \pm 0.02$ & 0.08 \\
\hline $\mathrm{m}$ & $0.14 \pm 0.09$ & $0.11 \pm 0.06$ & 0.52 & $0.13 \pm 0.02$ & $0.12 \pm 0 . .07$ & 0.62 \\
\hline $\mathrm{f}$ & $0.19 \pm 0.02$ & $0.15 \pm 0.82$ & 0.33 & $0.21 \pm 0.06$ & $0.19 \pm 0.07$ & 0.56 \\
\hline QH Plaque index & $2.31 \pm 1.23$ & $0.7 \pm 0.32$ & $0.001^{*}$ & $2.12 \pm 1.1$ & $1.8 \pm 0.92$ & 0.63 \\
\hline No of fractured teeth & $0.36 \pm 0.41$ & $0.39 \pm 0.6$ & 0.52 & $0.35 \pm 0.05$ & $0.36 \pm 0.04$ & 0.71 \\
\hline Correct Brushing frequency & $1.21 \pm 0.56$ & $1.83 \pm 0.4$ & $0.03^{*}$ & $1.2 \pm 0.32$ & $1.32 \pm 0.23$ & 0.09 \\
\hline Correct Brushing technique & $0.62 \pm 0.08$ & $1.55 \pm 0.23$ & $0.02^{*}$ & $0.72 \pm 0.09$ & $0.91 \pm 0.01$ & 0.56 \\
\hline $\begin{array}{l}\text { No. of sugary snacks a } \\
\text { day Less than } 3\end{array}$ & $1.62 \pm 0.5$ & $1.2 \pm 0.08$ & 0.06 & $1.63 \pm 0.23$ & $1.41 \pm .07$ & 0.21 \\
\hline More than 3 & $3.23 \pm 1.54$ & $2.82 \pm 1.65$ & 0.07 & $4.1 \pm 1.93$ & $3.98 \pm 1.87$ & 0.36 \\
\hline Use of Fluoridated toothpaste & $0.82 \pm 0.04$ & $1.66 \pm 0.86$ & $0.02^{*}$ & $0.62 \pm 0.02$ & $0.81 \pm 0.46$ & 0.65 \\
\hline Parents brushing twice & $0.22 \pm 0.05$ & $0.61 \pm 0.05$ & 0.07 & $0.27 \pm 0.06$ & $0.53 \pm 0.04$ & 0.09 \\
\hline
\end{tabular}

\section{RESULTS AND DISCUSSION}

The total number of the schools studied were 200 and in each school 12 students were examined. The final sample was 2400 for the study. In each school, 4 students from class 3,4 and 5 were examined. Two girls and two boys from each class were examined to maintain uniformity. Results showed that among the study group, there was a statistically significant difference between baseline and follow up data in the $\mathrm{D}$ component which was distributed as $1.47 \pm 0.95$ and $1.26 \pm 0.71$ respectively with $p$ value $=0.001$. Similarly there was a statistically significant difference between baseline and follow up data in the plaque level measured by $\mathrm{QH}$ plaque index which was distributed as $2.31 \pm 1.23$ and $0.7 \pm 0.32$ respectively with $p$ value $=0.001$. There was a significant difference found between baseline and follow up data among the study group in the brushing frequency which was distributed as $1.21 \pm 0.56$ and $1.83 \pm 0.4$ respectively with $p$ value $=$ 0.03 . Similarly there was a significant difference found between baseline and follow up data among the study group in the brushing technique which was distributed as $0.62 \pm 0.08$ and $1.55 \pm 0.23$ respectively with $p$ value $=0.02$. $($ table 1$)$
Results showed that there was a statistically significant difference between study group and control group at follow up data in the d component which was distributed as follows: $1.2 \pm 0.8$ and $1.34 \pm 0.02$ respectively with $p$ value $=0.05$. Similarly there was a statistically significant difference between study group and control group at follow up data in the plaque level measured using $\mathrm{QH}$ plaque index which was distributed as follows: $0.7 \pm 0.32$ and $1.8 \pm 0.92$ respectively with $p$ value $=0.0001$. There was a significant difference between study group and control group at follow up data in the brushing frequency which was distributed as follows: $1.83 \pm 0.4$ and $1.32 \pm 0.23$ respectively with $\mathrm{p}$ value $=0.001$. Similarly there was a statistically significant difference between study group and control group at follow up data in the brushing technique which was distributed as follows: $1.55 \pm 0.23$ and $0.97 \pm 0.01$ respectively with $p$ value $=0.012$

Results showed that there was a statistically significant difference between study group and control group at follow up data in the less than 3 sugary snacks per day component which was distributed as follows: $1.2 \pm 0.08$ and $1.41 \pm 0.07$ respectively with $p$ value $=0.031$. Similarly there was a statistically significant difference between study group and control group at follow 
up data in the more than 3 sugary snacks per day component which was distributed as follows: $2.82 \pm 1.65$ and $3.98 \pm 1.87$ respectively with $p$ value $=0.041$. Also there was a statistically significant difference between study group and control group at follow up data in the use of fluoridated toothpaste which was distributed as follows : $1.66 \pm 0.86$ and $0.81 \pm 0.46$ respectively with $p$ value $=0.006$ (table 2 )

Table 2. Distribution of different parameters in the final follow up data between both study and control groups using independent $\mathrm{T}$ test

\begin{tabular}{|l|c|c|c|}
\hline Parameters & $\begin{array}{c}\text { Study } \\
\text { group } \\
\text { group }\end{array}$ & $\begin{array}{c}\text { P } \\
\text { value }\end{array}$ \\
\hline $\mathrm{D}$ & $1.26 \pm 0.71$ & $1.31 \pm 0.76$ & 0.06 \\
\hline $\mathrm{M}$ & $0.09 \pm 0.05$ & $0.07 \pm 0.04$ & 0.21 \\
\hline $\mathrm{F}$ & $0.1 \pm 0.07$ & $0.1 \pm 0.04$ & 0.13 \\
\hline $\mathrm{d}$ & $1.2 \pm 0.8$ & $1.34 \pm 0.02$ & $0.05^{*}$ \\
\hline $\mathrm{m}$ & $0.11 \pm 0.06$ & $0.12 \pm 0 . .07$ & 0.51 \\
\hline $\mathrm{f}$ & $0.15 \pm 0.82$ & $0.19 \pm 0.07$ & 0.421 \\
\hline QH Plaque index & $0.7 \pm 0.32$ & $1.8 \pm 0.92$ & $0.0001^{*}$ \\
\hline No of fractured teeth & $0.39 \pm 0.6$ & $0.36 \pm 0.04$ & 0.462 \\
\hline $\begin{array}{l}\text { Correct Brushing } \\
\text { frequency }\end{array}$ & $1.83 \pm 0.4$ & $1.32 \pm 0.23$ & $0.001^{*}$ \\
\hline $\begin{array}{l}\text { Correct Brushing } \\
\text { technique }\end{array}$ & $1.55 \pm 0.23$ & $0.91 \pm 0.01$ & $0.012^{*}$ \\
\hline $\begin{array}{l}\text { No. of sugary snacks } \\
\text { per day Less than 3 }\end{array}$ & $1.2 \pm 0.08$ & $1.41 \pm .07$ & $0.031^{*}$ \\
\hline More than 3 & $2.82 \pm 1.65$ & $3.98 \pm 1.87$ & $0.041^{*}$ \\
\hline $\begin{array}{l}\text { Use of Fluoridated } \\
\text { toothpaste }\end{array}$ & $1.66 \pm 0.86$ & $0.81 \pm 0.46$ & $0.006^{*}$ \\
\hline \begin{tabular}{l} 
Parents brushing twice \\
\hline
\end{tabular} & $0.61 \pm 0.05$ & $0.53 \pm 0.04$ & 0.09 \\
\hline
\end{tabular}

Since 2000, substantial literature has emerged describing studies purporting to evaluate the effectiveness of various types and combinations of educational and behaviourmodification techniques. Studies concluded that quality of the evidence pertaining to the effectiveness of dental health education is poor (Brown, 1994; Kay and Locker, 1996) Dental health education can be delivered to individuals and groups in settings such as dental practice, schools, the workplace and day-care and residential settings for older adults. The importance of giving health education to children is that they are at an early point in their health career. Also, educating children can help us reach their families and community members. Logically, this provides a prime opportunity for influencing attitudes and behaviours at a formative stage(Habbu and Krishnappa, 2015) School children in the age group of 10- 15 years are in particular need of oral health promotion programmes because of high levels of plaque leading to gingivitis and early periodontitis(D'Cruz and Aradhya, 2013).

'Oral health education is a planned package of information, learning activities, or experiences that are intended to promote oral health' (Overton Dickinson, 2005). This level of knowledge is known to be necessary and one of the key determinants of behaviour change(Adair and Ashcroft, 2007). The cornerstone of the prevention of the two major oral diseases, dental caries and periodontal disease, is maintenance of a clean mouth or a clean tooth surface to be particular, that is, a tooth surface free from dental plaque. Well-planned and executed oral health promotion programmes could greatly accelerate the decline of the dental caries problem, periodontal problems, etc.(Harris, Garcia-Godoy and Nathe, 1999). The development of health education as a scientific discipline within dentistry has been slow. All too often action takes precedence over evaluation(D'Cruz and Aradhya, 2013)

Caries is the most prevalent dental disease both in the primary and the permanent dentition. And Schools are perhaps the best place for promoting oral health because approximately one billion children worldwide spend most of their daytime life there . Indeed, many habits of adults are formed when they are children of school age. Children are receptive, and health messages can easily be delivered to them.(Organization and Others, no date) In our present study , 30.9\% of the sample population were brushing twice daily in the baseline data. But in a study by Kuppusamy et al, 17\% only brushed twice(Kuppuswamy et al., 2014).

In our study, DMFT of the children were more than 1.5 which is similar in a study done by Mahesh kumar et al. The Decrease in D / d component and increase in $\mathrm{F} / \mathrm{f}$ component can depict the effect of the programme (Varma et al., 2005). Similarly the oral hygiene status of the were poor in the baseline and it increased significantly in the final data. The increase in the proportion of children who brush twice a day is attributed to the constant reminder in the test group schools. Similar findings were found in the study conducted by PE Peterson among school children in Wuhan, China (Petersen et al., 2004) There was no significant change in the brushing frequency of parents. But opposite findings were found in a similar study which involved mothers .This shows the involvement of mothers in these studies are important since it is children oriented (Makvandi et al., 2015)

Use of fluoridated tooth paste also increased from baseline to final data and similar finding was observed by a study by PE Peterson et al (Petersen et al., 2004). There was no significant difference in the consumption of sugared snacks and No. of fractured teeth. The main limitation of the study is the questions were subjective in nature. The children cant remember the factors like how many sugared snacks they have or the name of the tooth paste they use. Also the study was conducted in Government school children there cant be major disparities in socio economic status and diet.

\section{CONCLUSION}

The present study shows significant difference in DMFT, brushing frequencies, oral hygiene status which shows the train the trainees program was successful even with limitations. Further research may be needed in the weak 
areas of the study. children can easily taught a habit since they are young and teachers are the best way to teach them is to teach through teachers and parents. There is a need for a program by incorporating parents and teachers for better results.

\section{ACKNOWLEDGEMENTS}

Acknowledge all the staff of the department

\section{Conflict of Interest: Nil}

\section{REFERENCES}

Adair, P. and Ashcroft, A. (2007) 'Theory-based approaches to planning and evaluation of oral health education programmes', in Community Oral Health. Available at: https://pureportal.strath.ac.uk/en/ publications/theory-based-approaches-to-planningand-evaluation-of-oral-health.

Al-Haddad, K. A. et al. (2013) 'Assessment of Gingival Health Status among 5- and 12-Year-Old Children in Yemen: A Cross-Sectional Study', ISRN dentistry, 2013, p. 352621. doi: 10.1155/2013/352621.

Brown, L. F. (1994) 'Research in dental health education and health promotion: a review of the literature', Health education quarterly, 21(1), pp. 83-102. doi: 10.1177/109019819402100109.

D'Cruz, A. M. and Aradhya, S. (2013) 'Impact of oral health education on oral hygiene knowledge, practices, plaque control and gingival health of 13- to 15-year-old school children in Bangalore city', International Journal of Dental Hygiene, pp. 126-133. doi: 10.1111/ j.1601-5037.2012.00563.x.

Doifode, V. V., Ambadekar, N. N. and Lanewar, A. G. (2000) 'Assessment of oral health status and its association with some epidemiological factors in population of Nagpur, India', Indian journal of medical sciences, 54(7), pp. 261-269. Available at: https://www. ncbi.nlm.nih.gov/pubmed/11143844.

Goel, R. et al. (2014) 'Prevalence of dental caries among 12-15 years old school children in Ambala district of Haryana state', J Dent Res Updates, 1(1), pp. 01-05. Available at: http://ramauniversityjournal.com/ pdf_file/1-5.pdf.

Gopalakrishnan, S. et al. (2012) 'Prevalence of gingivitis and periodontitis in Mugappair population--Chennai, Tamilnadu', International Journal of Contemporary Dentistry, 2(6). Available at: http://www.edentj.com/ index.php/ijcd/article/viewArticle/639.

Gurunathan, D., Moses, J. and Arunachalam, S. K. (2018) 'Knowledge, Attitude, and Practice of Mothers regarding Oral Hygiene of Primary School children in Chennai, Tamil Nadu, India', International Journal of Clinical Pediatric Dentistry, pp. 338-343. doi: 10.5005/ jp-journals-10005-1535.

Habbu, S. G. and Krishnappa, P. (2015) 'Effectiveness of oral health education in children - a systematic review of current evidence (2005-2011)', International dental journal, 65(2), pp. 57-64. doi: 10.1111/idj.12137.

Harini, G. and Leelavathi, L. (2019) 'Nicotine Replacement Therapy for Smoking Cessation-An Overview', Indian Journal of Public Health Research \&t Development, 10(11), p. 3588. doi: 10.5958/09765506.2019.04144.5.

Harris, N. O., Garcia-Godoy, F. and Nathe, C. N. (1999) 'Primary preventive dentistry, 7th'. Pearson Education Inc. New Jersey.

Jürgensen, N., Petersen, P. E. and Others (2013) 'Promoting oral health of children through schools-Results from a WHO global survey 2012', Community dental health, 30(4), pp. 204-218. Available at: https:// bit.ly/2SQzAm2

Kannan, S. S. D. et al. (2017) 'AWARENESS AND ATTITUDE TOWARDS MASS DISASTER AND ITS MANAGEMENT AMONG HOUSE SURGEONS IN A DENTAL COLLEGE AND HOSPITAL IN CHENNAI, INDIA', in Disaster Management and Human Health Risk V. DISASTER MANAGEMENT 2017, Southampton UK: WIT Press (WIT Transactions on The Built Environment), pp. 121-129. doi: 10.2495/DMAN170121.

Kay, E. J. and Locker, D. (1996) 'Is dental health education effective? A systematic review of current evidence', Community dentistry and oral epidemiology, 24(4), pp. 231-235. doi: 10.1111/j.1600-0528.1996. tb00850.x.

Khatri, S. G. et al. (2019) 'Retention of moisture-tolerant fluoride-releasing sealant and amorphous calcium phosphate-containing sealant in 6-9-year-old children: A randomized controlled trial', Journal of the Indian Society of Pedodontics and Preventive Dentistry, 37(1), pp. 92-98. doi: 10.4103/JISPPD.JISPPD_173_18.

Klein, H., Palmer, C. E. and Knutson, J. W. (1938) ‘Studies on Dental Caries: I. Dental Status and Dental Needs of Elementary School Children', Public Health Reports (1896-1970), p. 751. doi: 10.2307/4582532.

Kumar, R. P., Pradeep Kumar, R. and Vijayalakshmi, B. (2017) 'Assessment of Fluoride Concentration in Ground Water in Madurai District, Tamil Nadu, India', Research Journal of Pharmacy and Technology, p. 309. doi: 10.5958/0974-360x.2017.00063.4.

Kumar, R. P. and Preethi, R. (2017) 'Assessment of Water Quality and Pollution of Porur, Chembarambakkam and Puzhal Lake', Journal of advanced pharmaceutical technology \&t research, 10(7), p. 2157. doi: 10.5958/0974360X.2017.00380.8.

Kuppuswamy, V. L. et al. (2014) 'Oral hygiene status, 
knowledge, perceptions and practices among school settings in rural South India', Oral health and dental management, 13(1), pp. 146-154. Available at: https:// www.ncbi.nlm.nih.gov/pubmed/24603932.

Last, J. M. and Wallace, R. B. (1992) Maxcy-RosenauLast Public Health and Preventive Medicine. Prentice Hall International. Available at: https://play.google. com/store/books/details?id=4kJrAAAAMAAJ.

Lukacs, J. R. and Largaespada, L. L. (2006) 'Explaining sex differences in dental caries prevalence: Saliva, hormones, and "life-history" etiologies', American Journal of Human Biology: The Official Journal of the Human Biology Association. Wiley Online Library, 18(4), pp. 540-555. Available at: https://onlinelibrary. wiley.com/doi/abs/10.1002/ajhb.20530.

Makvandi, Z. et al. (2015) 'Evaluation of an oral health intervention among mothers of young children: a clustered randomized trial', Journal of research in health sciences, 15(2), pp. 88-93. Available at: https://www. ncbi.nlm.nih.gov/pubmed/26175290.

Manchery, N. et al. (2019) 'Remineralization potential of dentifrice containing nanohydroxyapatite on artificial carious lesions of enamel: A comparative in vitro study', Dental research journal, 16(5), pp. 310-317. Available at: https://www.ncbi.nlm.nih.gov/pubmed/31543937.

Mathew, M. G. et al. (2020) 'Evaluation of adhesion of Streptococcus mutans, plaque accumulation on zirconia and stainless steel crowns, and surrounding gingival inflammation in primary molars: randomized controlled trial', Clinical oral investigations. doi: 10.1007/s00784020-03204-9.

Mk, J. S. and Umadevi, R. (2020) 'Knowledge, attitude and practice on oral hygiene among primary school children in an urban area of Kancheepuram district, Tamil Nadu', International Journal of Community Medicine and Public Health, 7(1), p. 311.

Mohapatra, S. et al. (2019) 'Assessment of Microhardness of Enamel Carious Like Lesions After Treatment with Nova Min, Bio Min and Remin Pro Containing Toothpastes: An in Vitro Study', Indian Journal of Public Health Research \& Development, p. 375. doi: 10.5958/0976-5506.2019.02832.8.

Naziya, K. B. et al. (2017) 'Prevalence of dental caries among primary schoolchildren in Chennai-A crosssectional study', Journal of Advanced Pharmacy Education \& Research| Apr-Jun, 7(2). Available at: https://www.speronline.com/japer/Articlefile/c/27_ JAPER_51_2017_20171031_V1.pdf.

Neralla, M. et al. (2019) 'Role of nutrition in rehabilitation of patients following surgery for oral squamous cell carcinoma', International Journal of Research in Pharmaceutical Sciences, pp. 3197-3203. doi: 10.26452/ijrps.v10i4.1622.
Organization, W. H. and Others (no date) 'Oral health promotion: an essential element of a health-promoting school. WHO information series on school health-Document eleven. Geneva: World Health Organization, 2003', World Health Organization.

Overton Dickinson, A. (2005) 'Community oral health education', Concepts in dental public health, 139, p. 157.

Pavithra, R. P., Preethi Pavithra, R. and Jayashri, P. (2019) 'Influence of Naturally Occurring Phytochemicals on Oral Health', Research Journal of Pharmacy and Technology, p. 3979. doi: 10.5958/0974-360x.2019.00685.1.

Petersen, P. E. et al. (2004) 'Effect of a school-based oral health education programme in Wuhan City, Peoples Republic of China', International dental journal. Wiley Online Library, 54(1), pp. 33-41. Available at: https:// bit.ly/316CZSn

Petersen, P. E. et al. (2015) 'School-based intervention for improving the oral health of children in southern Thailand', Community dental health, 32(1), pp. 44-50. Available at: https://www.ncbi.nlm.nih.gov/ pubmed/26263592.

Prabakar, J., John, J., Arumugham, I. M., Kumar, R. P. and Srisakthi, D. (2018) 'Comparative Evaluation of Retention, Cariostatic Effect and Discoloration of Conventional and Hydrophilic Sealants - A Single Blinded Randomized Split Mouth Clinical Trial', Contemporary clinical dentistry, 9(Suppl 2), pp. S233S239. doi: 10.4103/ccd.ccd_132_18.

Prabakar, J., John, J., Arumugham, I. M., Kumar, R. P. and Sakthi, D. S. (2018) 'Comparative Evaluation of the Viscosity and Length of Resin Tags of Conventional and Hydrophilic Pit and Fissure Sealants on Permanent Molars: An In vitro Study', Contemporary clinical dentistry, 9(3), pp. 388-394. doi: 10.4103/ccd. ccd_131_18.

Prabakar, J., John, J., Arumugham, I., et al. (2018) 'Comparing the effectiveness of probiotic, green tea, and chlorhexidine- and fluoride-containing dentifrices on oral microbial flora: A double-blind, randomized clinical trial', Contemporary Clinical Dentistry, p. 560. doi: 10.4103/ccd.ccd_659_18.

Prabakar, J., John, J. and Srisakthi, D. (2016) 'Prevalence of dental caries and treatment needs among school going children of Chandigarh', Indian journal of dental research: official publication of Indian Society for Dental Research, 27(5), pp. 547-552. doi: 10.4103/09709290.195683.

Pratha, A. A. and Prabakar, J. (2019) 'Comparing the effect of Carbonated and energy drinks on salivary $\mathrm{pH}-$ In Vivo Randomized Controlled Trial', Research Journal of Pharmacy and Technology. A \& V Publications, 12(10), pp. 4699-4702. Available at: http://www. 
indianjournals.com/ijor.aspx?target=ijor:rjpt\&tvolume $=12$ tissue $=10$ \&tarticle $=019$.

Priya, M. et al. (2013) 'Oral health attitudes, knowledge and practice among school children in Chennai, India', Journal of Education and Ethics in Dentistry. Medknow Publications and Media Pvt. Ltd., 3(1), p. 26. doi: 10.4103/0974-7761.126940.

Priya, P. R. G. et al. (2019) 'Effectiveness of school dental health education on the oral health status and knowledge of children: A systematic review', Indian journal of dental research: official publication of Indian Society for Dental Research. Medknow Publications and Media Pvt. Ltd., 30(3), p. 437. doi: 10.4103/ijdr. IJDR_805_18.

Samuel, S. R., Acharya, S. and Rao, J. C. (2020) 'School Interventions-based Prevention of Early-Childhood Caries among 3-5-year-old children from very low socioeconomic status: Two-year randomized trial', Journal of public health dentistry, 80(1), pp. 51-60. doi: 10.1111/jphd.12348.

Saravanan, S. et al. (2008) 'Caries prevalence and treatment needs of rural school children in Chidambaram Taluk, Tamil Nadu, South India', Indian journal of dental research: official publication of Indian Society for Dental Research, 19(3), pp. 186-190. doi: 10.4103/0970-9290.42948.

Saxena, S. and Shashikiran, N. D. (2010) 'Prevalence of dental caries and treatment needs among hemophilic children of Kota city, Rajasthan', Ann Essences Dent, 2, pp. 18-21. Available at: https://pdfs.semanticscholar.org /59fb/8ca94d3454864730501154c681f6a75bc2a3.pdf.

Shenoy, R. P., Salam, T. A. A. and Varghese, S. (2019) 'Prevalence and Clinical Parameters of Cervical Abrasion as a Function of Population, Age, Gender, and Toothbrushing Habits: A Systematic Review', World Journal of Dentistry, pp. 470-480. doi: 10.5005/ jp-journals-10015-1685.

Turesky, S., Gilmore, N. D. and Glickman, I. (1970) 'Reduced Plaque Formation by the Chloromethyl Analogue of Victamine C', Journal of Periodontology, pp. 41-43. doi: 10.1902/jop.1970.41.41.41.

Varma, R. B. et al. (2005) 'Oral health status of 5 years and 12 years school going children in Chennai city An epidemiological study', Journal of Indian Society of Pedodontics and Preventive Dentistry, p. 17. doi: 10.4103/0970-4388.16021.

Vishnu Prasad, S. et al. (2018) 'Report on oral health status and treatment needs of 5-15 years old children with sensory deficits in Chennai, India', Special care in dentistry: official publication of the American Association of Hospital Dentists, the Academy of Dentistry for the Handicapped, and the American Society for Geriatric Dentistry, 38(1), pp. 58-59. doi: 10.1111/scd.12267. 